\title{
EFFECT OF TEMPERATURE CHANGE ON THE COLOR OF RED AND YELLOW LOVIBOND GLASSES ${ }^{1}$
}

\author{
By Deane B. Judd ${ }^{2}$
}

\begin{abstract}
The spectral transmission at 12 wave lengths in the visible spectrum of two Lovibond glasses ( $35 \mathrm{Y}$ and $7.2 \mathrm{R}$ ) has been carefully determined at $15^{\circ} \mathrm{C}$. and at $40^{\circ}$ C. From these spectral transmission data the color changes corresponding to the temperature interval of $25^{\circ} \mathrm{C}$. have been computed. It was found, both for $35 \mathrm{Y}$ alone and for the $35 \mathrm{Y}+7.2 \mathrm{R}$ combination, that an increase of $25^{\circ} \mathrm{C}$. is the practical colorimetric equivalent of adding 0.2 in Lovibond red units. This difference is almost negligible in the color grading of cottonseed oil.

Preliminary work on two samples of cottonseed oil indicates that the oil changes in color with change in temperature even less than the glasses do. If all oils behave like these two samples, only extreme variations (more than $15^{\circ} \mathrm{C}$.) in temperature need be taken into account in color grading cottonseed oil with Lovibond glasses.
\end{abstract}

\section{CONTENTS}

I. Introduction

II. Method of measurement

III. Results

IV. Summary

\section{INTRODUCTION}

The present paper is a minor contribution to the program which has been in course at the Bureau of Standards for a number of years, and which has for its goal the attainment of agreement in color grading cottonseed oil. Considerable progress has been made in standardizing the Lovibond glasses themselves, ${ }^{3}$ and a start has been made toward standardizing the observers who use the glasses. ${ }^{4}$

${ }^{1}$ A preliminary synopsis of certain of the experimental results herein reported has appeared in the Oil and Fat Industries for April (p. 115) and May (p. 152); 1928.

2 This work was carried out at the instance of Irwin G. Priest and with the advice of Dr. K. S. Gibson, who had made some preliminary measurements, which he put at the disposal of the present author.

${ }^{3}$ Report on calibration of sixteen Lovibond red glasses of nominal value 7.6, by I. G. Priest, Cotton Oil Press; January, 1921. The Lovibond Color System, I. A Spectrophotometric Analysis of the Lovibond Glasses, by K. S. Gibson and F. K. Harris, B. S. Sci. Paper No. 547; Feb. 17, 1927. (Copies may be obtained from the Government Printing Office, Washington, D. C., at 15 cents each.) Standardizing the red and yellow Lovibond glasses, by Irwin G. Priest and K. S. Gibson, J. Opt. Soc. Am. and Rev. Sci. Inst., 16, p. 116; 1928. A study of 129 Lovibond red glasses with respect to the reliability of their nominal grades, by Deane B. Judd and Geraldine K. Walker, Oil and Fat Inds., 5, p. 16; 1928. See also Oil and Fat Inds., p. 433, December, 1927; p. 27, January, 1928; p. 58, February, 1928; p. 92, March, 1928; p. 114, April, 1928; p. 152, May, 1928; p. 184, June, 1928; p. 220, July, 1928.

4 Tests of the color sense of A. O. C. S. members and data on sensibility to change in Lovibond red, by Irwin G. Priest, Oil and Fat Inds., 5, p. 63; 1928. A much more comprehensive test was carried out at New Orleans in May, 1928, and a report of the results is in preparation. 
It is well known, however, that the absorption characteristics of many glass filters, and, hence, the color of those filters, change with temperature. If an oil were graded with a set of glasses at (say) $25^{\circ} \mathrm{C}$. at one time, and by the same observer at another time with the same set of glasses at $50^{\circ} \mathrm{C}$. (that is, the oil at $25^{\circ}$, the glasses at $50^{\circ}$ ), it might reasonably be expected, on account of the temperature change of the glasses, that the two grades would not agree. ${ }^{5}$ Whether the amount of this disagreement would be important or negligible, or whether it would result in too high or too low a grade for the oil, can not be predicted. It is the purpose of the present paper to give results of tests framed to decide these points.

\section{METHOD OF MEASUREMENT}

Determination of the relative spectral transmission ${ }^{6}$ of two glasses $\left(35 \mathrm{Y}_{\mathrm{BS10289 \textrm {C }}} \text { and } 7.1 \mathrm{R}_{\mathrm{Bs10288 \textrm {C }}}\right)^{7}$ separately and in combination were made for the following wave lengths: $\mathrm{Hg} 405, \mathrm{Hg} 436,470, \mathrm{Hg} 492$, $\mathrm{He} 502,530, \mathrm{Hg} 546,560, \mathrm{Hg} 578, \mathrm{He} 588,620$, and $680 \mathrm{~m} \mu, 20$ settings entering into each determination. The spectrophotometer used was the Koenig-Martens instrument equipped with a thermostat for control of the temperature of the sample. ${ }^{8}$ A single set of measurements consisted of one determination made at each of the above wave lengths with the sample at $15^{\circ} \mathrm{C}$., then one determination for each wave length with the sample at $40^{\circ} \mathrm{C}$., and, finally, one determination at each of wave lengths $405,436,492,502,546,578$, and $588 \mathrm{~m} \mu$ with the sample again at $15^{\circ} \mathrm{C}$. Two sets each were made for the three filters (that is, for the two separate glasses and their combination). Special precautions were taken to insure accurate setting of wave length; and, at the low temperature $\left(15^{\circ} \mathrm{C}\right.$.) frequent inspection was made to be sure that no moisture had collected on the cover glasses.

${ }^{3}$ It should be remarked that we consider the effect of changing the temperature of the glasses alone, not the oil, because the scope of this paper does not include a study of the oils graded in practice by Lovibond glasses. The working situation, as above stated, is of more than academic interest, however, because there is some reason to believe that many oils either do not change color on being heated (see footnote 18, p. 865) or, at least, change much less than the glasses, in which case the temperature of the oil is a matter of indifference. Furthermore, if there exist oils whose color does change significantly with temperature, still the condition of having the glasses hotter than the oil sample is a technically important one because often in practice, many samples of oil are graded consecutively against the same $35 \mathrm{Y}$ glass which soon attains the temperature of the tintometer, while each oil sample, remaining a relatively short time in the tintometer, fails to heat to much above room temperature.

${ }_{6}$ The actual spectral transmissions were not measured because it was found necessary to cover the glasses being tested with two pieces of clear glass. This was done so that the glass itself could be kept at all times at the temperature of the thermostat undisturbed by currents of air from the room. The relative spectral transmissions that were obtained are very close to the actual spectral transmissions because the reflection losses due to the two cover glasses were compensated for by two plates of glass in the comparison beam.

7 These numbers ( 35 and 7.1) are the numerals engraved by the maker.

8 This instrument forms a part of the regular equipment of the colorimetry section of the Bureau of Standards. It is described in full in Bureau of Standards Journal of Research, 1 (No. 30); 1928, by H. J. McNicholas, "Equipment for Routine Spectral Transmission and Reflection Measurements." 
TABLE 1.-Spectral transmissions for $35 Y, 7.2 R$, and $35 Y+7.2 R$ and change of spectral transmission with temperature $(\theta)$

[The values of $T_{\lambda}$ are not exactly the ones adopted as standard by Priest and Gibson. They refer to actua]

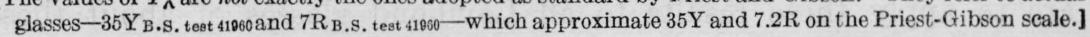

\begin{tabular}{|c|c|c|c|c|c|c|}
\hline \multirow{2}{*}{$\begin{array}{c}\lambda \text { in } \\
\mathrm{m} \mu\end{array}$} & \multicolumn{2}{|c|}{$35 \mathrm{Y}$} & \multicolumn{2}{|c|}{$7.2 \mathrm{R}$} & \multicolumn{2}{|c|}{$35 \mathrm{Y}+7.2 \mathrm{R}$} \\
\hline & $T_{\lambda}$ & {$\left[\frac{d T_{\lambda}}{d \theta}\right]_{\lambda}$} & $T_{\lambda}$ & {$\left[\frac{d T_{\lambda}}{d \theta}\right]_{\lambda}$} & $T_{\lambda}$ & {$\left[\frac{d T_{\lambda}}{d \theta}\right]$} \\
\hline $\begin{array}{r}380 \\
90\end{array}$ & $\begin{array}{r}0.000 \\
.000\end{array}$ & $\begin{array}{l}x 10^{2} \\
0.000 \\
.000\end{array}$ & $\begin{array}{r}0.449 \\
.456\end{array}$ & $\begin{array}{c}x 10^{2} \\
+0.012 \\
+.012\end{array}$ & $\begin{array}{r}0.000 \\
.000\end{array}$ & $\begin{array}{l}x 10^{2} \\
0.000 \\
.000\end{array}$ \\
\hline $\begin{array}{r}400 \\
10 \\
20 \\
30 \\
40\end{array}$ & $\begin{array}{l}.000 \\
.000 \\
.000 \\
.000 \\
.000\end{array}$ & $\begin{array}{l}.000 \\
.000 \\
.000 \\
.000 \\
.000\end{array}$ & $\begin{array}{l}.463 \\
.468 \\
.473 \\
.475 \\
.476\end{array}$ & $\begin{array}{r}+.012 \\
+.011 \\
+.011 \\
+.010 \\
+.010\end{array}$ & $\begin{array}{l}.000 \\
.000 \\
.000 \\
.000 \\
.000\end{array}$ & $\begin{array}{l}.000 \\
.000 \\
.000 \\
.000 \\
.000\end{array}$ \\
\hline $\begin{array}{r}450 \\
60 \\
70 \\
80 \\
90\end{array}$ & $\begin{array}{l}.000 \\
.003 \\
.022 \\
.081 \\
.187\end{array}$ & $\begin{array}{r}.000 \\
-.001 \\
-.022 \\
-.050 \\
-.080\end{array}$ & $\begin{array}{l}.475 \\
.471 \\
.460 \\
.436 \\
.393\end{array}$ & $\begin{array}{r}+.010 \\
+.010 \\
+.010 \\
+.011 \\
+.014\end{array}$ & $\begin{array}{l}.000 \\
.001 \\
.010 \\
.035 \\
.073\end{array}$ & $\begin{array}{r}.000 \\
.000 \\
-.010 \\
-.020 \\
-.027\end{array}$ \\
\hline $\begin{array}{r}500 \\
10 \\
20 \\
30 \\
40\end{array}$ & $\begin{array}{l}.313 \\
.434 \\
.540 \\
.623 \\
.682\end{array}$ & $\begin{array}{l}-.103 \\
-.095 \\
-.078 \\
-.065 \\
-.050\end{array}$ & $\begin{array}{l}.333 \\
.256 \\
.184 \\
.147 \\
.167\end{array}$ & $\begin{array}{r}+.017 \\
+.018 \\
+.015 \\
+.009 \\
+.004\end{array}$ & $\begin{array}{l}.104 \\
.111 \\
.099 \\
.092 \\
.114\end{array}$ & $\begin{array}{l}-.027 \\
-.016 \\
-.006 \\
-.004 \\
-.006\end{array}$ \\
\hline $\begin{array}{r}550 \\
60 \\
70 \\
80 \\
90\end{array}$ & $\begin{array}{l}.720 \\
.738 \\
.742 \\
.735 \\
.719\end{array}$ & $\begin{array}{l}-.037 \\
-.025 \\
-.015 \\
-.005 \\
+.005\end{array}$ & $\begin{array}{l}.253 \\
.378 \\
.495 \\
.589 \\
.661\end{array}$ & $\begin{array}{r}-.006 \\
-.018 \\
-.019 \\
-.019 \\
-.017\end{array}$ & $\begin{array}{l}.182 \\
.279 \\
.367 \\
.433 \\
.475\end{array}$ & $\begin{array}{l}-.013 \\
-.023 \\
-.022 \\
-.017 \\
-.009\end{array}$ \\
\hline $\begin{array}{r}600 \\
10 \\
20 \\
30 \\
40\end{array}$ & $\begin{array}{l}.698 \\
.671 \\
.645 \\
.620 \\
.602\end{array}$ & $\begin{array}{r}+.014 \\
+.020 \\
+.023 \\
+.020 \\
+.017\end{array}$ & $\begin{array}{l}.713 \\
.752 \\
.780 \\
.800 \\
.815\end{array}$ & $\begin{array}{r}-.015 \\
-.013 \\
-.011 \\
-.008 \\
-.006\end{array}$ & $\begin{array}{l}.498 \\
.505 \\
.503 \\
.496 \\
.491\end{array}$ & $\begin{array}{r}-.001 \\
+.006 \\
+.010 \\
+.011 \\
+.010\end{array}$ \\
\hline $\begin{array}{r}650 \\
60 \\
70 \\
80 \\
90\end{array}$ & $\begin{array}{l}.591 \\
.590 \\
.599 \\
.611 \\
.617\end{array}$ & $\begin{array}{l}+.013 \\
+.007 \\
\pm .000 \\
-.008 \\
-.013\end{array}$ & $\begin{array}{l}.828 \\
.838 \\
.847 \\
.855 \\
.860\end{array}$ & $\begin{array}{r}-.004 \\
-.002 \\
-.001 \\
.000 \\
.000\end{array}$ & $\begin{array}{l}.489 \\
.494 \\
.507 \\
.522 \\
.531\end{array}$ & $\begin{array}{l}+.008 \\
+.005 \\
-.001 \\
-.007 \\
-.011\end{array}$ \\
\hline $\begin{array}{r}700 \\
10 \\
20\end{array}$ & $\begin{array}{l}.629 \\
.650 \\
.678\end{array}$ & $\begin{array}{l}-.016 \\
-.018 \\
-.019\end{array}$ & $\begin{array}{l}.866 \\
.870 \\
.873\end{array}$ & $\begin{array}{l}.000 \\
.000 \\
.000\end{array}$ & $\begin{array}{l}.545 \\
.566 \\
.592\end{array}$ & $\begin{array}{l}-.014 \\
-.015 \\
-.016\end{array}$ \\
\hline
\end{tabular}

\section{RESULTS}

From the values of relative spectral transmission so obtained for the three filters, it has been possible, by averaging and interpolation, to obtain for every $10 \mathrm{~m} \mu$ the change in spectral transmission $\left(T_{\lambda}\right)$ per degree change in temperature $(\theta)$. This quantity $\left(d T_{\lambda} / d \theta\right)_{\lambda}$ is tabulated (see Table 1) for $35 \mathrm{Y}, 7.2 \mathrm{R}$, and $35 \mathrm{Y}+7.2 \mathrm{R},{ }^{9}$ together with the approximate values of spectral transmission for those filters. ${ }^{10}$

- This Lovibond red numeral, and those which follow, refer to the red scale established by Priest and Gibson, J. Opt. Soc. Am. and Rev. Sci. Inst., 16, p. 116; 1928.

${ }_{10}$ The transmissions given are for illustrative purposes only; they do not represent accurately the particular glasses studied, but rather $35 \mathrm{YB}$. s. test 41960 and $7 \mathrm{RB}$. s. test 41960 which may be taken as typical of the spectral transmission that an average Lovibond glass of grade $35 \mathrm{Y}$ (or $7.2 \mathrm{R}$ or $35 \mathrm{Y}+7.2 \mathrm{R}$ ) yields. This is the type of spectral transmission to which the temperature coefficients of spectral transmission $\left(d \mathrm{~T}_{\lambda} / d \theta\right)_{\lambda}$ apply. The quantities in Table 1 are not independent, of course, but are connected, for each wave length, by the relations:

and

$T_{35 \mathrm{Y}+7.2 \mathrm{R}}=\left(T_{35 \mathrm{Y}}\right)\left(T_{7.2 \mathrm{R}}\right)$

$(d T / d \theta)_{35 \mathrm{Y}+7.2 \mathrm{R}}=\left(T_{7.2 \mathrm{R}}\right)\left[(d T / d \theta)_{35 \mathrm{Y}}\right]+\left(T_{35 \mathrm{Y}}\right)\left[(d T / d \theta)_{7.2 \mathrm{R}}\right]$ 
It is plain that these results really refer only to the specific Lovibond glasses tested and only for the temperatures 15 and $40^{\circ} \mathrm{C}$. If we are to apply these results to all Lovibond glasses of about these grades and to all ordinary temperatures, as would be convenient, we must accept the following assumptions: (1) The spectral transmissions of these Lovibond glasses for all wave lengths are assumed to vary in a sensibly linear way with temperature; and (2) all Lovibond glasses of about these grades are assumed to change in spectral transmission with temperature approximately as have the two which were studied. It is reasonable to suppose that the first assumption is correct because the changes in transmission found are so small ${ }^{11}$; we expect the second to hold because the same coloring materials ${ }^{12}$ enter into all sets of Lovibond glasses.

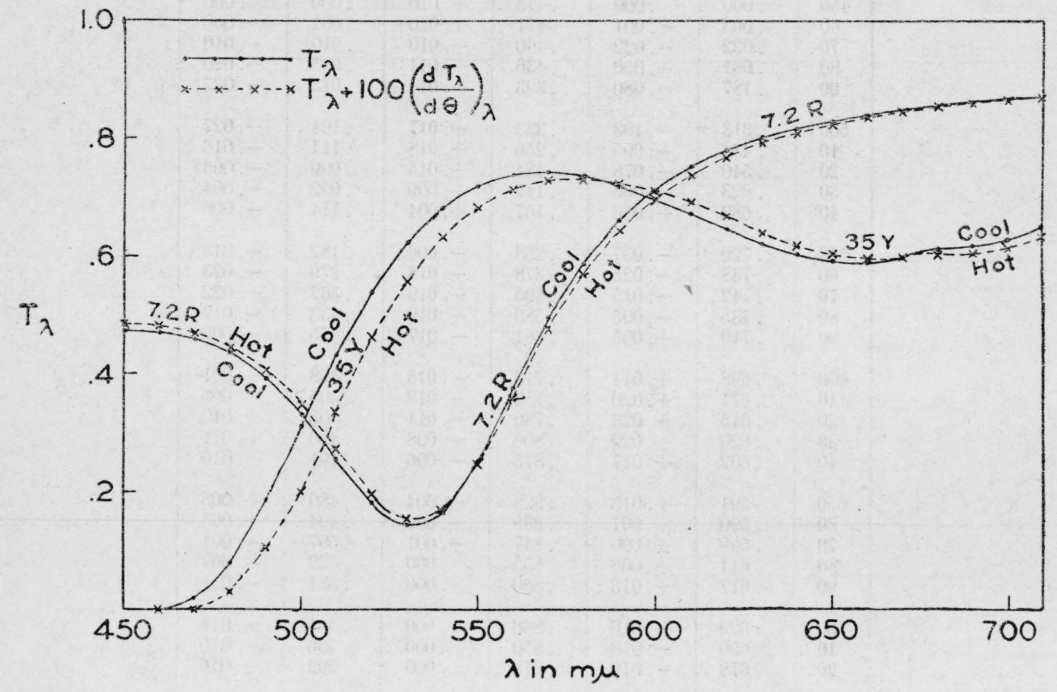

FIG. 1.-Spectral transmission of $35 Y$ glass and $7.2 R$ glass at different temperatures

Increasing the temperature of either the red or the yellow Lovibond glass shifts fthe curve of spectral transmission toward longer wave lengths, but the change of the yellow glass is considerably greater.

Figure 1 serves to illustrate the results presented in Table 1. The solid curves are plotted from the spectral transmissions plus 100 times the change in transmission per ${ }^{\circ} \mathrm{C}$. rise in temperature. The solid curves of spectral transmission may be taken as typical of $35 \mathrm{Y}$ glasses and 7.2R glasses at about $20^{\circ} \mathrm{C}$; ; the two assumptions just discussed are correct, the dotted curves may be taken as typical of

11 The largest change found was 0.001 per ${ }^{\circ} \mathrm{C}$. This amounts to 0.025 in transmission for the $25^{\circ}$ temperature interval studied. A change of 0.005 in transmission is about the smallest whose direction can be determined with certainty from two determinations of 20 settings each.

12 The Lovibond filters are all flashed glasses; the absorbing material in the yellow glasses is principally silver; in the red glasses, gold. (See J. W. Lovibond, On a new method of colour analysis by means of the tintometer, J. Soc. Chem. Ind, 9, p. 15; 1890). The effect of temperature change on the light-absorbing properties of these kinds of glasses apparently has never before been studied. 
the same glasses at about $120^{\circ} \mathrm{C} .^{13}$ It may be noted that the effect of increasing the temperature of the glasses is to shift the curve of spectral transmission somewhat toward the red. Both glasses show this sort of shift, but the shift for the $35 \mathrm{Y}$ glass is perhaps four or five times as great as that for the $7.2 \mathrm{R}$ glass.

The next problem is to convert these changes in spectral transmission into colorimetric terms. It may be seen that the $35 \mathrm{Y}$ glass or the combination $35 \mathrm{Y}+7.2 \mathrm{R}$ must become more reddish on being heated, but we wish now to know how much this increase amounts to in Lovibond units. Accordingly; we assume that the glasses are illuminated by sunlight (Abbot-Priest sun) and compute the color characteristics of the transmitted light. ${ }^{14}$ Table 2 shows the results of this computation for $35 \mathrm{Y}$ and $35 \mathrm{Y}+7.2 \mathrm{R}$, both for the spectral transmissions given in Table 1 , and for those which are typical of the glasses after a rise of $25^{\circ} \mathrm{C} . .^{15}$ The symbols in the first column refer to the trilinear coordinates $(r, g, b)$, the dominant wave length $(\Lambda)$, the colorimetric purity $(P)$, and the transmission for Abbot-Priest sun $\left(T_{\mathrm{s}}\right)$. It will be noticed that, in both cases, heating the glasses results: (1) In a redder color (note that the $r$-coordinate has increased at the expense of the $g$ and $b$ coordinates; note also that the dominant wave length and purity have increased) and, (2) in a darker color (note the decrease in transmission for sunlight).

TABLE $2^{1}$

\begin{tabular}{|c|c|c|c|c|c|c|}
\hline \multicolumn{3}{|c|}{$35 \mathrm{Y}$} & \multicolumn{3}{|c|}{$35 \mathrm{Y}+7.2 \mathrm{R}$} \\
\cline { 2 - 5 } & $\begin{array}{c}\text { Normal } \\
\text { tem- } \\
\text { perature }\end{array}$ & $\begin{array}{c}25^{\circ} \\
\text { above } \\
\text { normal }\end{array}$ & Change & $\begin{array}{c}\text { Normal } \\
\text { tem- } \\
\text { perature }\end{array}$ & $\begin{array}{c}25^{\circ} \\
\text { above } \\
\text { normal }\end{array}$ & Change \\
\hline$r$ & 0.5035 & 0.5073 & +0.0038 & 0.5961 & 0.5994 & +0.0032 \\
$g$ & .4595 & .4580 & -.0015 & .3782 & .3768 & -.0014 \\
$b$ & .0370 & .0347 & -.0023 & .0257 & .0239 & -.0018 \\
$\Lambda$ & $575.97 \mathrm{~m}$ & 576.43 & +.46 & 587.2 & 587.4 & +.2 \\
$P$ & .931 & .935 & +.004 & .951 & .953 & +.002 \\
$T_{\mathrm{B}}$ & .622 & .614 & -.008 & .268 & .265 & -.003 \\
\hline
\end{tabular}

1 These computed quantities are based on the Optical Society of America visual response functions as extrapolated by Priest and Gibson (J. Opt. Soc. Am. and Rev. Sci. Inst., 10, p. 230; 1925). The standard "neutral" stimulus taken is Abbot-Priest sun (J. Opt. Soc. Am. and Rev. Sci. Inst., 12, p. 479; 1926).

Note.-The data for $r, g, b, \Lambda, P$, and $T$ are not the standard values for the Priest-Gibson scale. They are to be understood merely as characterizing particular glasses ( $35 \mathrm{Y}$ B. s. test 41960 and $7 \mathrm{R}_{\mathrm{B}}$. s. test 41980$)$ which are approximate realizations of the standard $35 \mathrm{Y}$ and $7.2 \mathrm{R}$.

${ }_{13}$ Of course, the glasses are not ordinarily used at such high temparatures as $120^{\circ} \mathrm{C}$., but if a small temperature difference (say $10^{\circ}$ ) were taken, the transmission differences plotted on the graph would be too small to be easily apparent. Figure 1, therefore, serves to illustrate the kind of transmission changes which occur, though to a proportionally smaller degree, for usual temperature differences (say 10 or $20^{\circ} \mathrm{C}$.).

${ }^{14}$ For methods of computing from spectral transmission, the trilinear coordinates $(r, g, b)$, dominant wave length $(\Lambda)$, colorimetric purity $(P)$, and transmission for sunlight $\left(T_{\mathrm{\theta}}\right)$, søe: J. Opt. Soc. Am. and Rev. Sci. Inst., 6, p. 527; 1922; 9, p. 503; 1924; 13, p. 123; 1926; and 13, p. 133; 1926, particularly the first one cited.

${ }_{15}$ The transmissions typical of the glasses $25^{\circ} \mathrm{C}$. above normal are computed as $T_{\lambda}+25\left(d \mathrm{~T}_{\lambda} / d \theta\right)_{\lambda}$. This temperature difference is chosen because it is about the maximum difference which may be expected to arise in the ordinary use of the Lovibond glasses. It is also the difference at which the glasses were measured for change in spectral transmission. 
Now, if a small amount of Lovibond red were added to these filters the resulting combination would also be redder and darker. It might conceivably turn out that heating the glasses is the exact colorimetric equivalent of adding a certain amount of Lovibond red to them; and if this should be the case, a convenient way of specifying the temperature effect would be its equivalent in Lovibond red. In order to find out how the color changes specified in Table 2 compare with the color changes produced by adding Lovibond red to the filters, the $r$ and $g$ trilinear coordinates from Table 2 are plotted on the same graph (fig. 2) with the $r$ and $g$ trilinear coordinates of the ideal red scale (established by Priest and Gibson) in combination with a glass that is an approximate $35 \mathrm{Y}$.
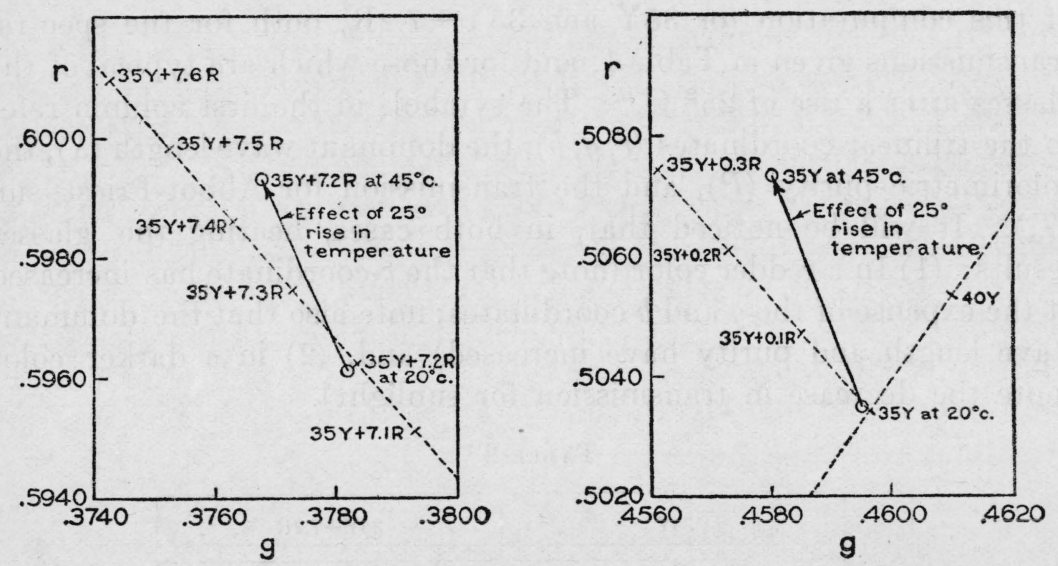

FIG. 2.-Graphic representation of the color change of the $35 Y$ glass and the $35 Y+7.2 R$ combination due to change in their temperature

The color change produced by heating the red and yellow Lovibond glasses is nearly the same in both cases as is produced by adding Lovibond red, but it is not exactly the same kind of change. An increase of $25^{\circ} \mathrm{C}$. is practically equivalent in either case to the addition of 0.2 in Lovibond red units.

Examination of Figure 2 shows that, both for $35 \mathrm{Y}$ and for $35 \mathrm{Y}+7.2 \mathrm{R}$, heating the glasses is not exactly equivalent to the addition of Lovibond red, but that it is nearly equivalent. Heating either the $35 \mathrm{Y}$ or the $35 \mathrm{Y}+7.2 \mathrm{R}$ filter $25^{\circ} \mathrm{C}$. above normal is nearly equivalent to adding 0.2 Lovibond red. In more specific terms, a $35 \mathrm{Y}$ glass at $50^{\circ} \mathrm{C}$. would be a very close hue match ${ }^{16}$ for the $35 \mathrm{Y}+0.2 \mathrm{R}$ combination (on the Priest-Gibson scale) at $25^{\circ} \mathrm{C}$. The saturation equivalence would not be perfect, but probably the satura-

${ }^{16}$ Although Figure 2 suggests strongly that the temperature effect expressed in Lovibond red units is very nearly the same at $35 \mathrm{Y}+7.2 \mathrm{R}$ as it is at $35 \mathrm{Y}$, it is not obvious why we may say that $35 \mathrm{Y}$ at $45^{\circ} \mathrm{C}$. has the same hue as $35 \mathrm{Y}+0.2 \mathrm{R}$ at $20^{\circ} \mathrm{C}$. This assertion is based on the fact that $r / g$ for $35 \mathrm{Y}$ at $45^{\circ} \mathrm{C}$. is neariy the same as $r / g$ for $35 \mathrm{Y}+0.2 \mathrm{R}$ at $20^{\circ} \mathrm{C}$. It has been shown by Abney (Proc. Roy. Soc., A., 83; 1909) that constant $r / g$ for these colors is synonymous with constant hue. To show that the hue change due to temperature change (that is, the change in $r / g$ due to temperature change) is the same as the hue change due to the addition of a given amount of Lovibond red both at $35 \mathrm{Y}$ and at $35 \mathrm{Y}+7.2 \mathrm{R}$, we proceed to compute for these two colors how much Lovibond red $(\Delta N)$ must be added to produce the same increment in hue $(\Delta r / g)$ as was produced by raising the temperature $25^{\circ} \mathrm{C}$. We have at hand the trilinear coordinates $(r, g, b)$ for all values of $N$ on the $35 \mathrm{Y}+\mathrm{NR}$ scale (some of these are shown in fig. 2); hence we can compute $r / g$ as a function of $N$. From this curve (which is sensibly linear for $\Delta N=0.2$ ) we may obtain $d N / d(r / g$ ) 
tion difference would be too small to be detected. A perfect hue and saturation match would result if some Lovibond yellow (perhaps about three units) were added as well as the 0.2 Lovibond red. This three units of Lovibond yellow is not perceptible with certainty, however. Since a rise in temperature of $25^{\circ} \mathrm{C}$. is very closely equivalent in hue and saturation to the addition of 0.2 Lovibond red unit both at $35 \mathrm{Y}$ and at $35 \mathrm{Y}+7.2 \mathrm{R}$, it is probably safe to conclude that this equivalence holds all along the $35 \mathrm{Y}+\mathrm{NR}$ scale from $35 \mathrm{Y}$ up to $35 \mathrm{Y}+7.2 \mathrm{R}$, or, perhaps, further.

It has also been shown that a rise of $25^{\circ} \mathrm{C}$. makes the $35 \mathrm{Y}$ glass darker by 0.008 (see Table 2 ) and the $35 \mathrm{Y}+7.2 \mathrm{R}$ combination darker by 0.003 . If 0.2 in Lovibond red units were added to $35 \mathrm{Y}^{17}$ the transmission for sunlight would decrease by 0.012 , which is not far from the darkening $(0.008)$ produced by heating the glass $25^{\circ} \mathrm{C}$. If the 0.2 in Lovibond red units were added to the $35 \mathrm{Y}+7.2 \mathrm{R}$ combination, the transmission for sunlight would decrease by 0.004 which is not far from the darkening $(0.003)$ produced by heating the combination $25^{\circ} \mathrm{C}$. Hence, we may conclude that not only is a rise in temperature by $25^{\circ} \mathrm{C}$. of any of the glass combinations between $35 \mathrm{Y}$ and $35 \mathrm{Y}+7.2 \mathrm{R}$ practically equivalent in hue and saturation to the addition of 0.2 in Lovibond red units, but also that it is practically equivalent in brilliance (brilliance is degree of lightness or darkness) as well. ${ }^{18}$

for any value of $N$, though, to be sure, we shall need this value only for $N=O$ and for $N=7.2$. The required increments in Lovibond red $(\Delta N)$ may be computed as:

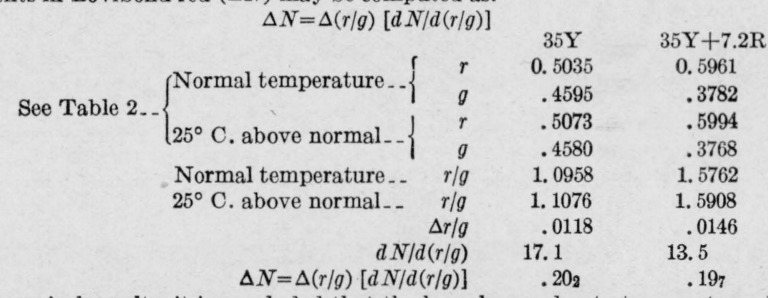

From these numerical results, it is concluded that the hue change due to temperature change of $25^{\circ} \mathrm{C}$. is closely equal to the hue change produced by adding $0.2 \mathrm{R}$, both at $35 \mathrm{Y}$ and at $35 \mathrm{Y}+7.2 \mathrm{R}$.

${ }_{17} \mathrm{It}$ is not meant to add a 0.2 red glass to the $35 \mathrm{Y}$ glass in the usual way because the resulting combination would be darker by about 8 per cent of its transmission from reflection losses, alone, due to the two added surfaces. If this addition of 0.2 in Lovibond red units is to be thought of as the combination of an actual red glass of 0.2 Lovibond grade (on the Priest-Gibson scale) with the $35 \mathrm{Y}$ glass, the conclusions about to be made will only be valid if these two glasses are in optical contact so that the loss in transmission due to two additional reflecting surfaces will be avoided.

${ }^{18}$ It may well be pointed out here that if the oil to be measured by these glasses should change in the same way with temperature as the glasses do, it might not be necessary to take any account of the change of the glasses. It would only be necessary to keep the oil and the glasses at about the same temperature. However, two samples of oil, measured in the same way the glasses were measured, did not show any certain change in hue or saturation. Both samples of oil became somewhat lighter on heating (increase in the transmission for sunlight of about 0.020 ), and did not, on cooling, darken quite to their original state. If the observer who reads the oils mistakes darkness for redness, this nonselective change in transmission might be important; for, to get a corresponding change in transmission for sunlight on the $35 \mathrm{Y}+\mathrm{NR}$ scale, nearly a whole Lovibond red unit must be taken. Furthermore, this change is in the opposite direction from that shown by the glasses; that is, the two oils studied grew lighter, the glasses grew darker, on being heated. The conclusions based on the change of the absorbing characteristics of oil due to change in temperature are valid only for the two samples studied. It is not justifiable to assume, as was done in the case of the glasses, that all cottonseed oils are like the two samples studied, because, unlike the glasses, the oils do not contain unvarying coloring materials. 


\section{SUMMARY}

1. The changes in spectral transmission produced by heating a Lovibond $35 \mathrm{Y}$ glass and a Lovibond $35 \mathrm{Y}+7.2 \mathrm{R}$ glass combination have been determined for the temperature interval of 15 to $40^{\circ} \mathrm{C}$.

2 . From the changes in spectral transmission the color changes resulting from the glass filters illuminated by sunlight have been computed by making use of the Optical Society of America visual response functions.

3 . It is shown that, for Lovibond glasses between $35 \mathrm{Y}$ and $35 \mathrm{Y}+7.2 \mathrm{R}$ on the Priest-Gibson scale, an increase in temperature of $25^{\circ} \mathrm{C}$. is practically equivalent to the addition of 0.2 in Lovibond red units.

Washington, June, 1928. 